\title{
Educational attainment in patients with congenital heart disease: a comprehensive systematic review and meta-analysis
}

Lucia Cocomello ${ }^{1 *}$, Arnaldo Dimagli², Giovanni Biglino ${ }^{3,4}$, Rosie Cornish ${ }^{1,5}$, Massimo Caputo $^{2}$ and

Deborah A. Lawlor ${ }^{1,5,6}$

\begin{abstract}
Background: Our aim was to comprehensively review published evidence on the association between having a congenital heart disease (CHD) compared with not, on educational attainment (i.e. not obtaining a university degree, completing secondary education, or completing any vocational training vs. obtaining/completing) in adults.

Method: Studies were eligible if they reported the rate, odds, or proportion of level of educational attainment in adults by whether or not they had a CHD.

Result: Out of 1537 articles screened, we identified 11 ( $N=104,585$ participants, 10,487 with CHD), 10 ( $N=167,470$ participants, 11,820 with $\mathrm{CHD}$ ), and 8 ( $N=150,813$ participants, 9817 with $\mathrm{CHD}$ ) studies reporting information on university education, secondary education, and vocational training, respectively in both CHD and non-CHD participants. Compared to their non-CHD peers, CHD patients were more likely not to obtain a university degree $(\mathrm{OR}=1.38,95 \%$ $\mathrm{Cl}[1.16,1.65])$, complete secondary education $(\mathrm{OR}=1.33,95 \% \mathrm{Cl}[1.09,1.61])$ or vocational training $(\mathrm{OR}=1.11,95 \%$ $\mathrm{Cl}[0.98,1.26])$. For all three outcomes there was evidence of between study heterogeneity, with geographical area contributing to this heterogeneity.

Conclusion: This systematic review identified all available published data on educational attainment in CHD patients. Despite broad inclusion criteria we identified relatively few studies that included a comparison group from the same population, and amongst those that did, few adjusted for key confounders. Pooled analyses suggest evidence of lower levels of educational attainment in patients with CHD when compared to non-CHD peers. The extent to which this may be explained by confounding factors, such as parental education, or mediated by treatments is not possible to discern from the current research literature.
\end{abstract}

Keywords: Congenital heart disease, Educational attainment, Systematic review

\section{Background}

Congenital heart defects (CHD) are among the most common types of birth defects, affecting between 6 and 8 per 1000 of live born children [1]. Advances in the

\footnotetext{
${ }^{*}$ Correspondence: nn18747@bristol.ac.uk

1 MRC Integrative Epidemiology Unit, Oakfield House, Oakfield Grove, Bristol BS8 2BN, UK

Full list of author information is available at the end of the article
}

management of patients with CHD have enabled substantial improvement in long-term survival even for those with serious cardiac defects [2], with more than $90 \%$ of patients with CHD reaching adulthood life [3]. Therefore, the implications of CHD in adult patients have become a key focus of CHD research [4].

An area of particular interest is whether those with CHD have similar educational attainment to their contemporaries without CHD [5]. This is important as 
higher educational attainment is related to better quality of life, as well as a longer, healthier and disease free life in the general population [6-8], and it is plausible this would also be the case among those with CHD. However, whether educational attainment is lower in CHD patients remains unclear. The different conclusions from individual studies of the relationship between CHD and educational attainment may reflect differences in disease severity between studies as it is plausible that more severe CHD would have a greater impact on educational attainment [9]. As both treatments for CHD, and educational systems and policies, vary across time and between geographic regions it is also plausible that associations might vary by these factors.

The aim of this study was to undertake a comprehensive systematic review and, where appropriate, meta-analysis of all available evidence in order to determine: (a) the association between having a CHD compared with not, on three measures of educational attainment (obtaining a university degree, completing secondary education and completing vocational training) in adults; and (b) if possible with the identified studies, determine whether the associations of $\mathrm{CHD}$ with educational attainment vary by disease severity, geographic region and over time. In order to provide comprehensive information for patients, education, and health service providers we included all studies in our review in which the rates, odds, or proportion of any of the three educational outcomes could be obtained in adult CHD patients, irrespective of whether the main aim of the study was to look at the association of having a CHD with educational attainment or not.

\section{Method}

The study was conducted in accordance with the Metaanalyses Of Observational Studies in Epidemiology guidelines for Meta-Analyses and Systematic Reviews of Observational Studies [10].

\section{Data sources and searches}

A comprehensive search of electronic databases MEDLINE and EMBASE was conducted for studies published between the beginning of each database and March 2021 (details provided as Additional file 1). Reference lists of relevant studies were also examined to identify any additional relevant studies not identified in the search.

\section{Selection of studies and data extraction}

All abstracts were screened, and full text assessed for eligibility by two independently reviewers (LC and AD), conflicts were resolved by consensus and, where necessary, through discussion with the other co-authors.

\section{Eligibility criteria}

Original research of any study design that fulfilled the criteria below was eligible; this meant we could include population-based register studies, cohort studies, case control studies, cross-sectional studies, and randomised controlled trials if they included relevant data. We sought studies that included a comparator group of non-CHD patients from the same population for aim (a) (see aims at end of introduction), but we also included studies that only included CHD patients. Whilst these studies may not address the question for patients and their families as to whether they are likely to be as successful in school as their peers, our PPI work suggested it was still helpful to know what proportion of those with CHD obtain a university degree or complete secondary education. Furthermore, we identified a source that provided summary data, stratified by age, of the proportion of people in most countries of the world achieving the three educational outcomes explored in this study (see below). Thus, for most studies that only had data in CHD patients we were still able to compare them to overall educational levels in their country.

Studies were therefore eligible if they reported (or provided sufficient data for us to be able to calculate) the rate, odds, or proportion of level of educational attainment in adults (aged 18 years of age or older) with a history of any CHD. They were also eligible if CHD patients had not undergone procedures, whilst those in which patients had undergone procedures were eligible irrespective of the type, timing, or number of repeat procedures. We also included studies irrespective of whether the aim was to explore educational attainment in patients with CHD or not. The cut-off of 18 years was chosen so that we could assess differences in educational attainment at the age of completion of compulsory education in most high-income countries, and with measures (completing a university degree, secondary education, or vocational training) that are likely to influence future life chances. In initial screening we included studies with a lower age threshold (16 years or older) and, in the data extraction process, explored whether it was possible to obtain results for those only 18 years or older.

\section{Outcomes}

Whether comparing CHD patients to a control group without CHD or comparing the proportion with an educational outcome in CHD patients to country-level proportions, we studied three outcomes, and studies could be included if they had data on at least one of these:

- Obtaining a university degree (including undergraduate and postgraduate degrees) 
- Completing secondary education

- Completing vocational training

The outcomes were all analysed as 'not achieving' (e.g., not obtaining a university degree).

To avoid double counting data, separate articles reporting educational outcomes in the same patient group were evaluated and the article providing most complete information (largest sample or more recent study) was selected for inclusion.

\section{Data extraction}

Data were extracted independently by two reviewers (LC, AD). For each study, we extracted information on the total number of patients with CHD and those without and, where provided, the number of $\mathrm{CHD}$ and non-CHD participants who achieved each educational attainment measure. We also extracted information on the age and sex of participants, the geographical region of the study, year of publication and the severity of the disease. Three authors (LC, RC, DAL) a priori defined key confounders of the association between CHD and educational attainment. Confounders are by definition factors that could plausibly affect the risk of having CHD and the educational outcomes [11]. Maternal pregnancy characteristics (e.g. higher early/pre-pregnancy BMI, smoking and alcohol) have been hypothesised to influence CHD risk in offspring, though whether these are all causal factors for offspring educational attainment is debatable [12]. As these are likely to be influenced by maternal/parental education, which is an important determinant of offspring educational attainment, we considered parental education to be a key confounder. CHD risk also varies by parental age at birth and ethnicity, which in turn influence educational attainment. Therefore, we considered the three key confounders to be parental education, age, ethnicity and extracted information on whether studies adjusted for these. In the risk of bias assessment (see below) we considered a study to have minimal risk of bias from residual confounding if they had adjusted for parental education, ethnicity and age, allowing that adjustment to be for either one, or both, of the parents. All relevant results in whatever form were extracted (i.e., any of: adjusted or unadjusted odds ratios, risk ratios, hazard ratios, differences in risk, with relevant standard errors or confidence intervals, or proportion of participants with each educational measure), with information on what analyses were used to obtain the results.

\section{Obtaining country level summary data on educational attainment}

We extracted summary data from 'Education at a Glance' on the proportion of adults (25-64 years old) with each of the three educational attainment outcomes for the country of residence and years of data collection of each included study. Education at a Glance is the authoritative source for information on the state of education around the world [13]. It produces annual reports with the first being published in 1998 and the most recent 2019. The age strata 25-64 years was chosen because it most closely matched the ages across the studies identified in our systematic search.

\section{Risk of bias assessment}

Risk of bias was assessed by two independent reviewers (LC, AD) and disagreements were resolved by discussion with all co-authors.

Risk of bias assessment was performed using the risk of bias instrument for non-randomized studies of exposure [14], which is based on seven items: (1) confounding, (2) selection of participants, (3) classification of exposure, (4) departures from intended exposure, (5) missing data, (6) measurement of outcomes and (7) selection of reported results.

\section{Statistical analysis}

To address patient and family concerns (see Patient and Public Involvement) we quantified (i) educational attainment in patients with CHD compared to their peers without CHD and (ii) educational attainment in CHD patients using all available data.

\section{Comparing educational attainment in patients with CHD to those without CHD}

I. We originally planned to perform the main analysis of the association of CHD with educational attainment by pooling individual study estimates with and without adjustment for prespecified confounders. However, some studies did not control for any covariables and, where they did, most controlled only for age and sex. Only one study controlled for all prespecified key confounders by using a sibling control group. One study adjusted for ethnicity, education and other markers of socioeconomic position and another study parental ethnicity and education. We therefore estimated the pooled odds ratio of not completing different levels of education for CHD patients compared non-CHD controls with and without adjustment only for sex and age. A random effects model (i.e., DerSimonian and Laird) was used to estimate the odds ratios of educational attainment because we a priori assumed that the differences between studies-for example due to differences in terms of which CHDs were included, region of residence of participants 
and year of study-might influence results. The results from the random effect meta-analyses are the average effects across all different populations. To aid interpretation of the random effects result we calculated prediction intervals, with a method proposed by Higgins et al. [15] based on a $t$ distribution with $\mathrm{K}-2$ degrees of freedom, where $\mathrm{K}$ corresponds to the number of studies in the metaanalysis. A prediction interval provides a range within which the potential effect of CHD in any different setting/population will lie, as this may be different from the average effect [16].

We measured between study heterogeneity using the Cochrane $\mathrm{Q}$ statistic and $\mathrm{I}^{2}$ and explored possible sources of heterogeneity through subgroup analyses. Our pre-specified subgroup analyses were: proportion of CHD patients with severe disease $(\geq 10 \%$ or $<10 \%$ ); year of the study $(\geq 2015$ or $<2015)$, geographic region (Europe, North America, Middle East, Asia, Australia), and proportion of females $(\geq 50 \%$ or $<50 \%$ ). Exact categories (for geographical regions) and thresholds (for severity and proportion of females were decided after data extraction based on what was feasible and to obtain a similar number of studies (and participants) in each group being compared, where possible. Test for subgroup differences (chi-squared) was used to compare effects between groups.

II. We reported a head to head comparison of between proportions of education attainment reported in CHD patients in studies without a comparison group, and data from the general population using data from 'Education at a Glance' (adults aged 24-64 in the country/countries from which the CHD patients came from) [17].

\section{Estimating the proportion of CHD patients attaining each education level}

Finally, we estimated the pooled proportions of CHD patients with each measure of educational attainment across all studies (i.e., both studies that included a nonCHD comparison group and those that did not). Pooled proportions for each outcome of interest (i.e., university, secondary and vocational education attainment) were obtained using the inverse variance method, random effects model (DerSimonian and Laird).

Publication bias was evaluated using funnel plots and Egger's test.

All statistical analyses were performed using R ( R Core Team (2019). R Foundation for Statistical Computing, Vienna, Austria. URL https://www.R-project.org/) and
meta-R package (Guido Schwarzer (2007), meta: An R package for meta-analysis, $\mathrm{R}$ News.

\section{Patient and public involvement}

Prior to analyses, we looked at the work carried out by the CHD charity Little Hearts Matter [18], which works continuously with patients and their family to identify areas of public interest. They indicated education as a key concern for patients and families [19, 20] and this represented a key motivation to undertake this review. At completion of the analysis we met with a group of patients and relatives (two male adult patients, two female adult patients, two mothers of adult patients with CHD) who confirmed that education was a very relevant aspect of their life and a key concern when growing up. In some cases, it was suggested that special educational support could have been useful to them, but this was not provided as not perceived to be necessary by the school. Dissemination of the review's findings amongst relevant audience (e.g., CHD patients and families, but also teachers) was also recommended.

\section{Results}

The titles and abstracts of 1537 articles were screened. Of these, 64 papers were selected and reviewed for inclusion criteria. With detailed review, 22 of these were excluded. Reasons for exclusion were educational attainment not reported $(n=5)$, overlapping/duplicate studies $(\mathrm{n}=8$, Additional file 1 : Table $\mathrm{S} 1$ ); only children included $(n=9)$. A total of 42 studies were eligible for inclusion in the review (Fig. 1).

\section{Characteristics of studies included}

An overview of the included studies is presented in Tables 1 and 2. The association of CHD with educational attainment was the main aim for 14 (33\% of total) studies [21-34], while in the remaining 28 (67\% of total) studies [35-62] it was not. For most of those, information on education attainment was extracted from tables describing study population characteristics. Information on university degree, completing secondary education, and vocational training was available in 39 (93\%), 32 (76\%) and 15 (36\%) studies respectively, with studies able to contribute to more than one outcome. A nonCHD comparison group was included in 12 (29\%) of the studies (Table 1) while the remaining 30 reported only on CHD patients (Table 2). The source of the comparison groups varied between studies, but CHD and non-CHD groups were obtained from same underlying population. One study included both a general (unrelated) population comparison group and a sibling (of the CHD patients) comparison group [57]. As none of the other studies had a sibling comparison group we included results from the 


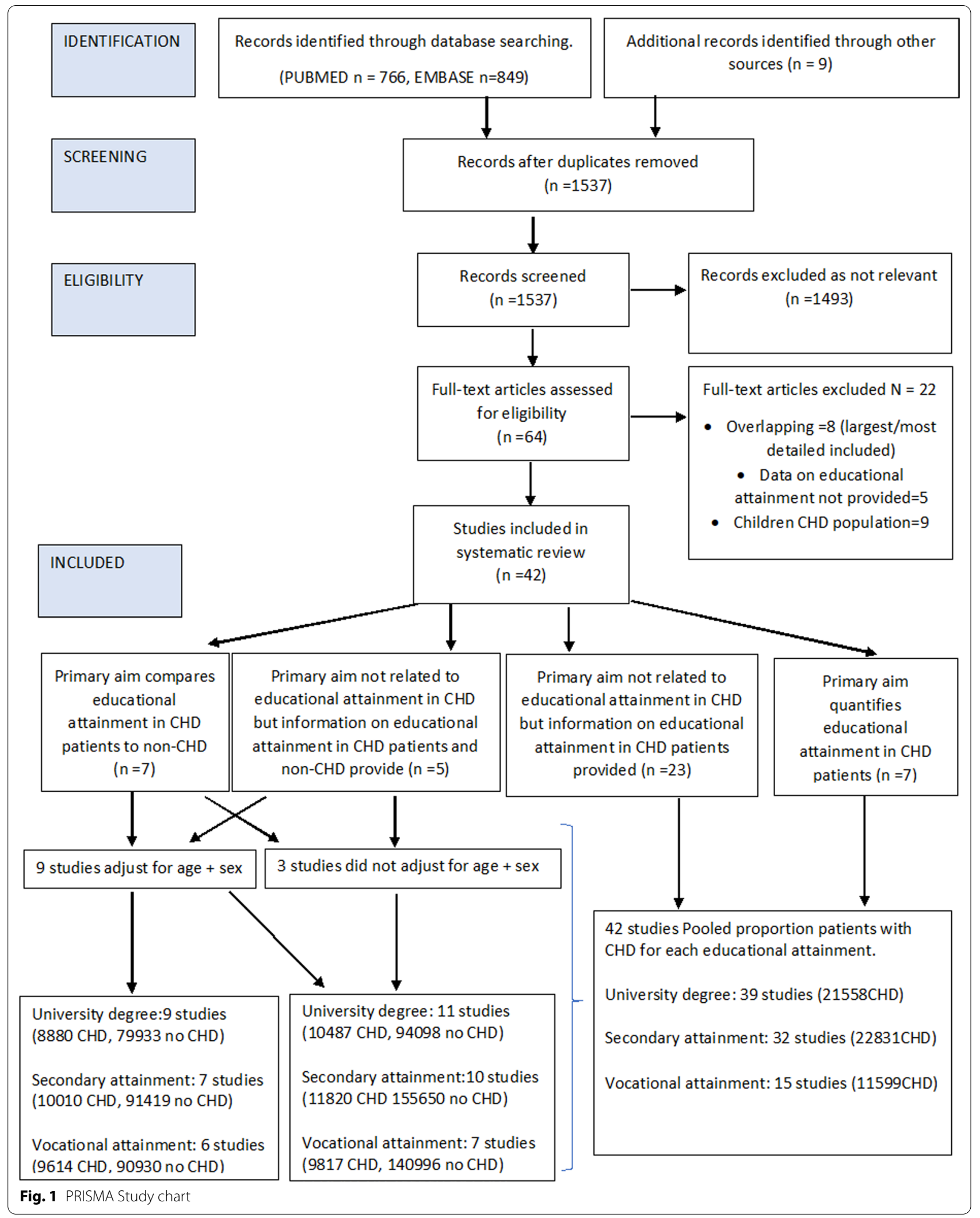




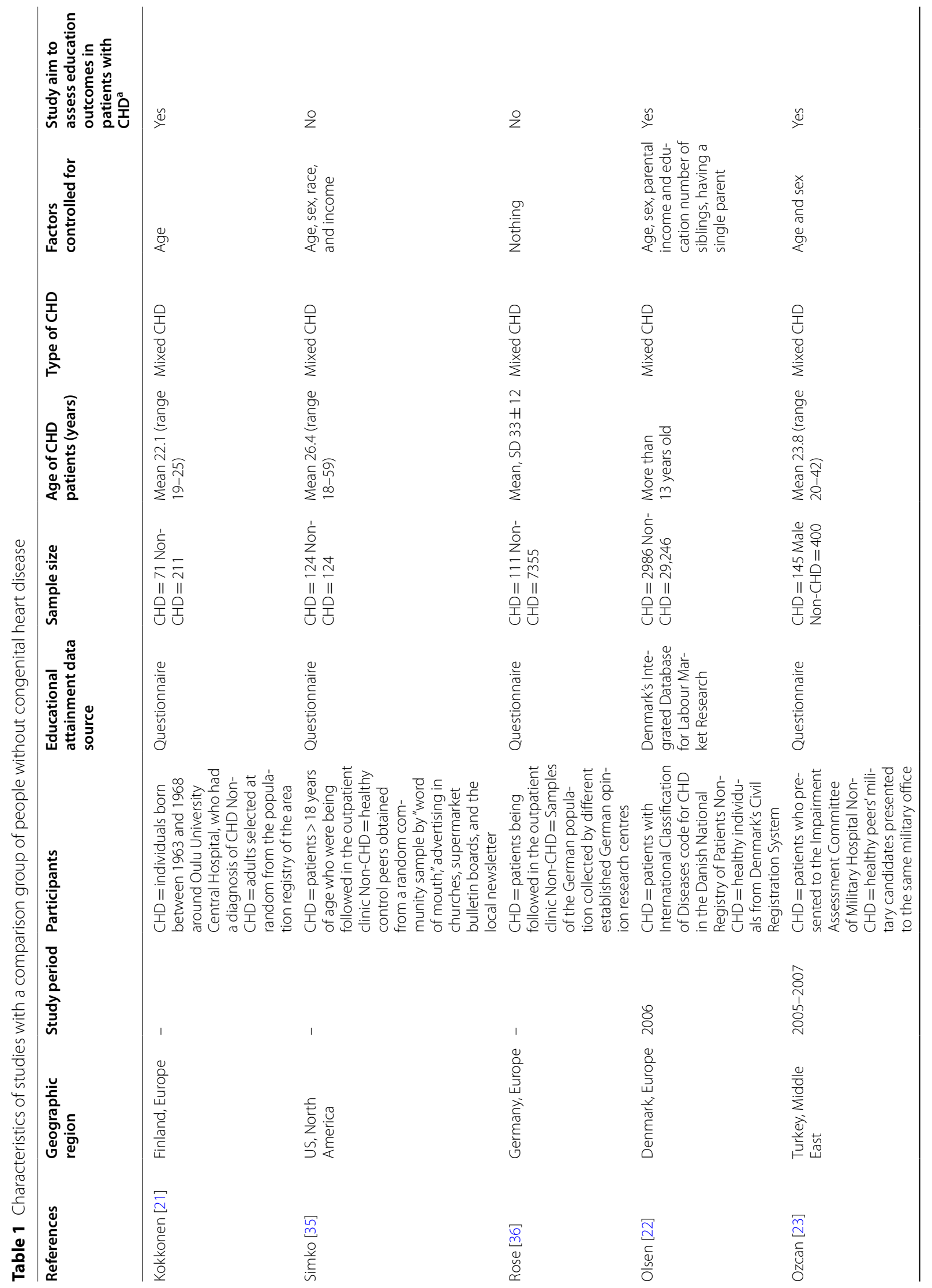




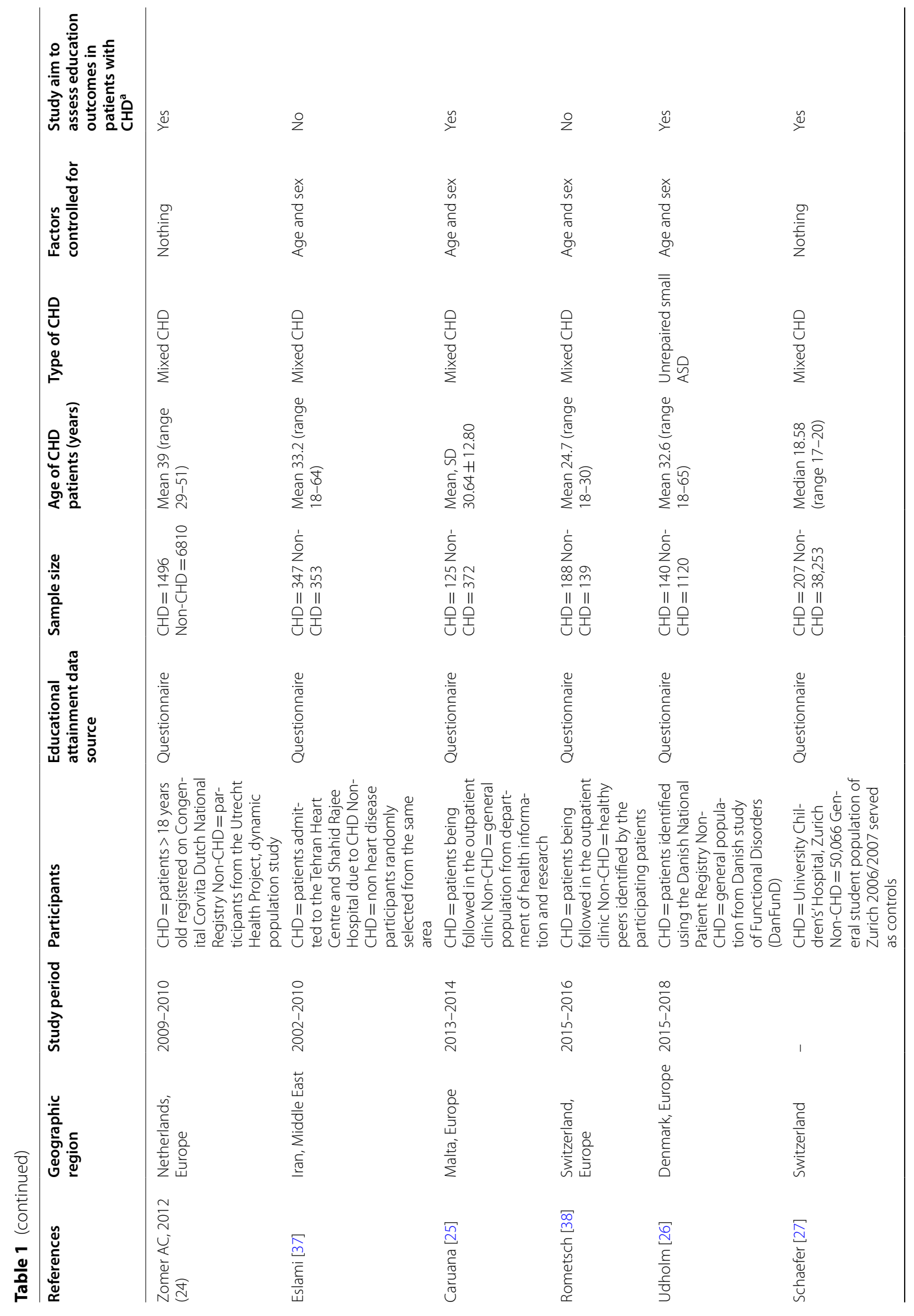




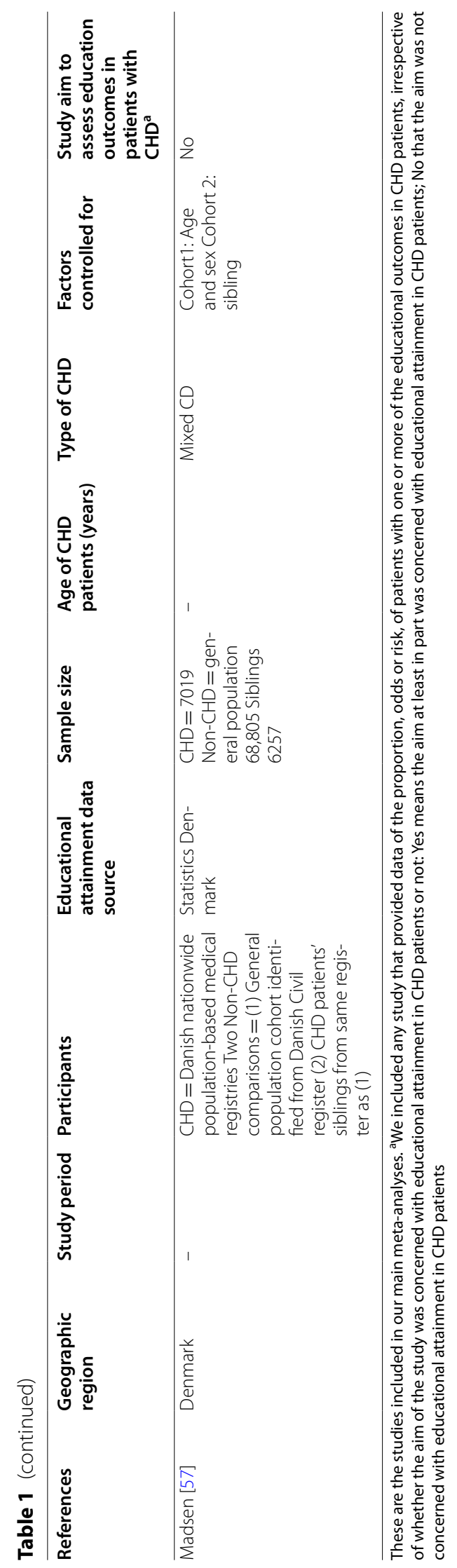




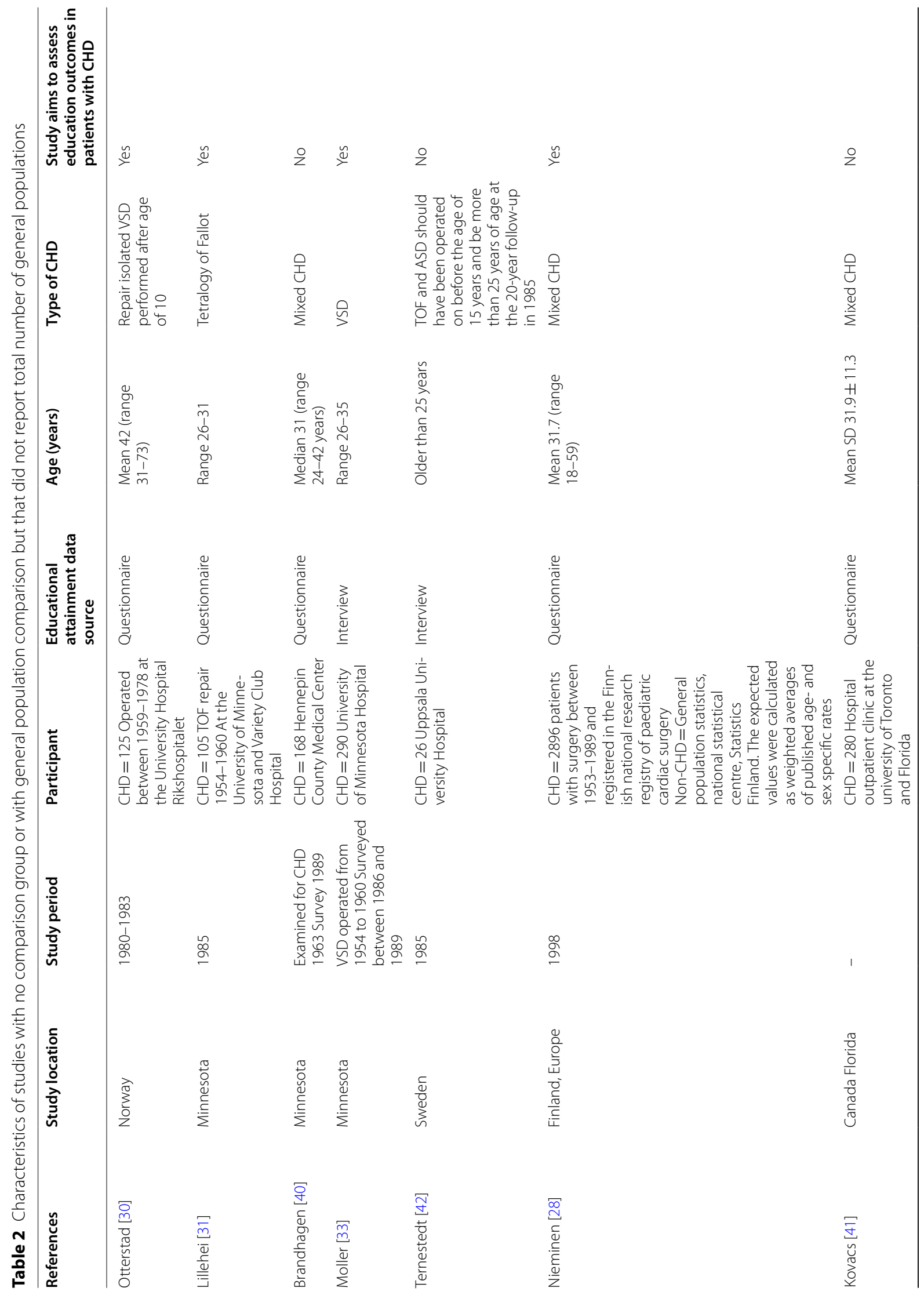




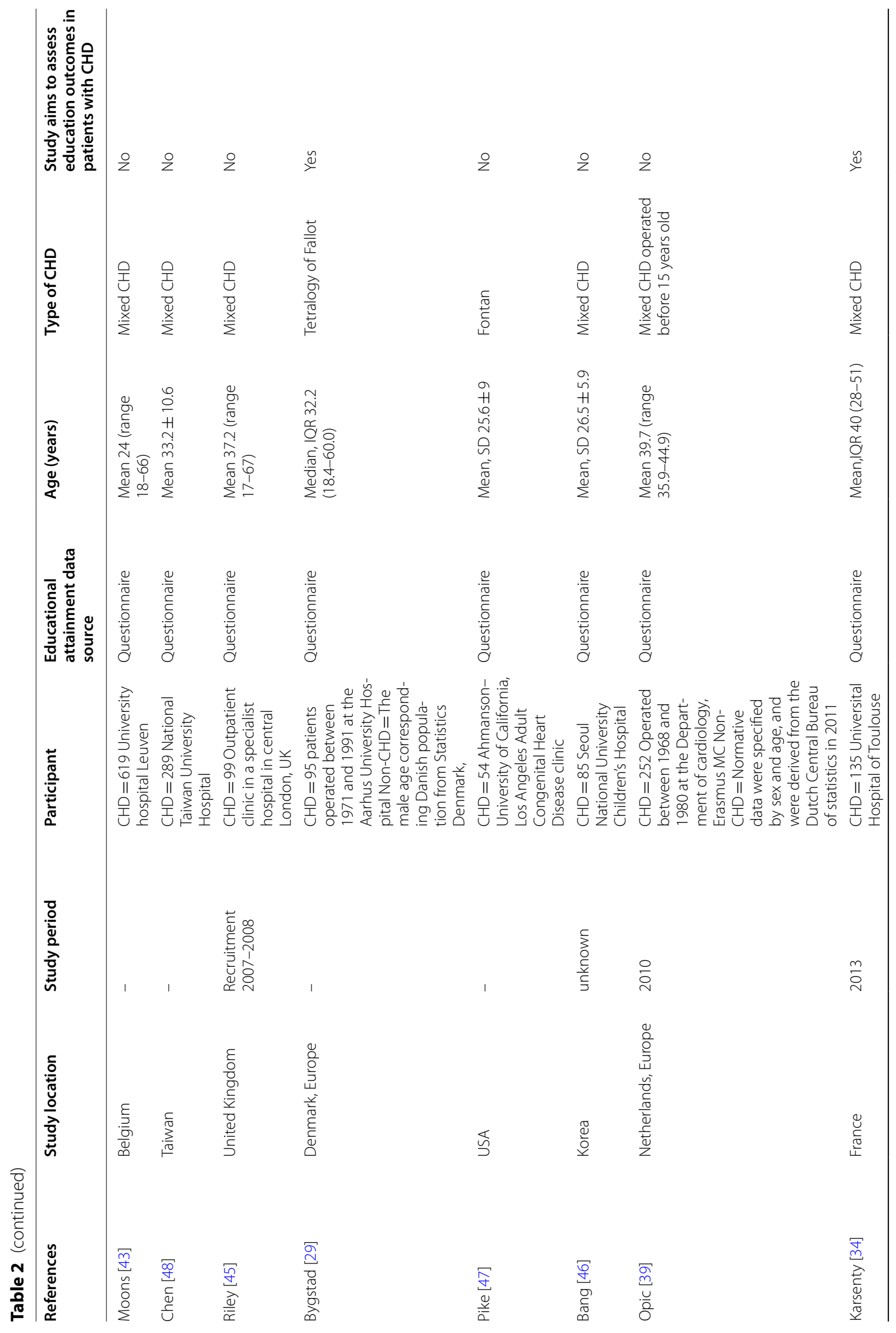




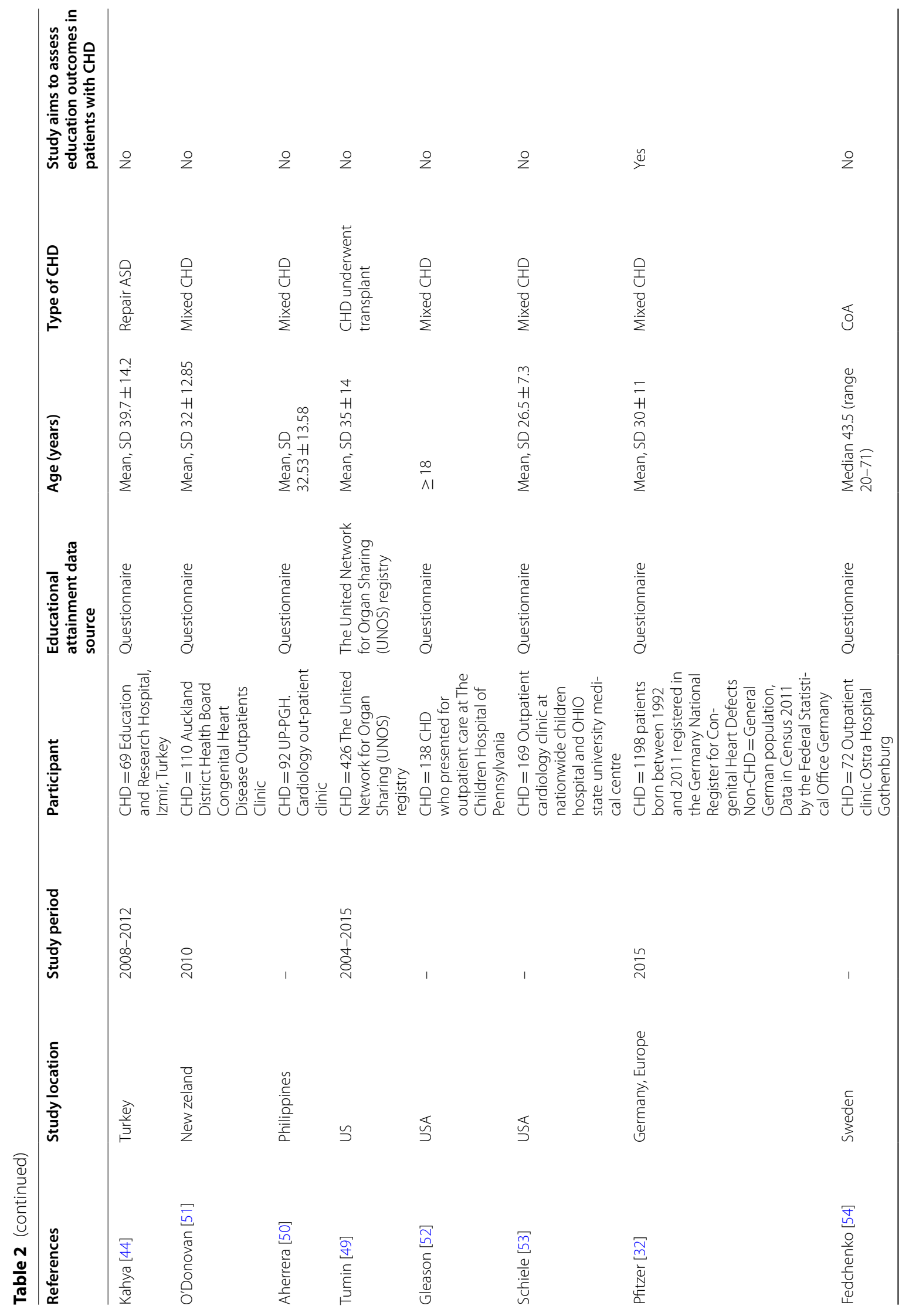




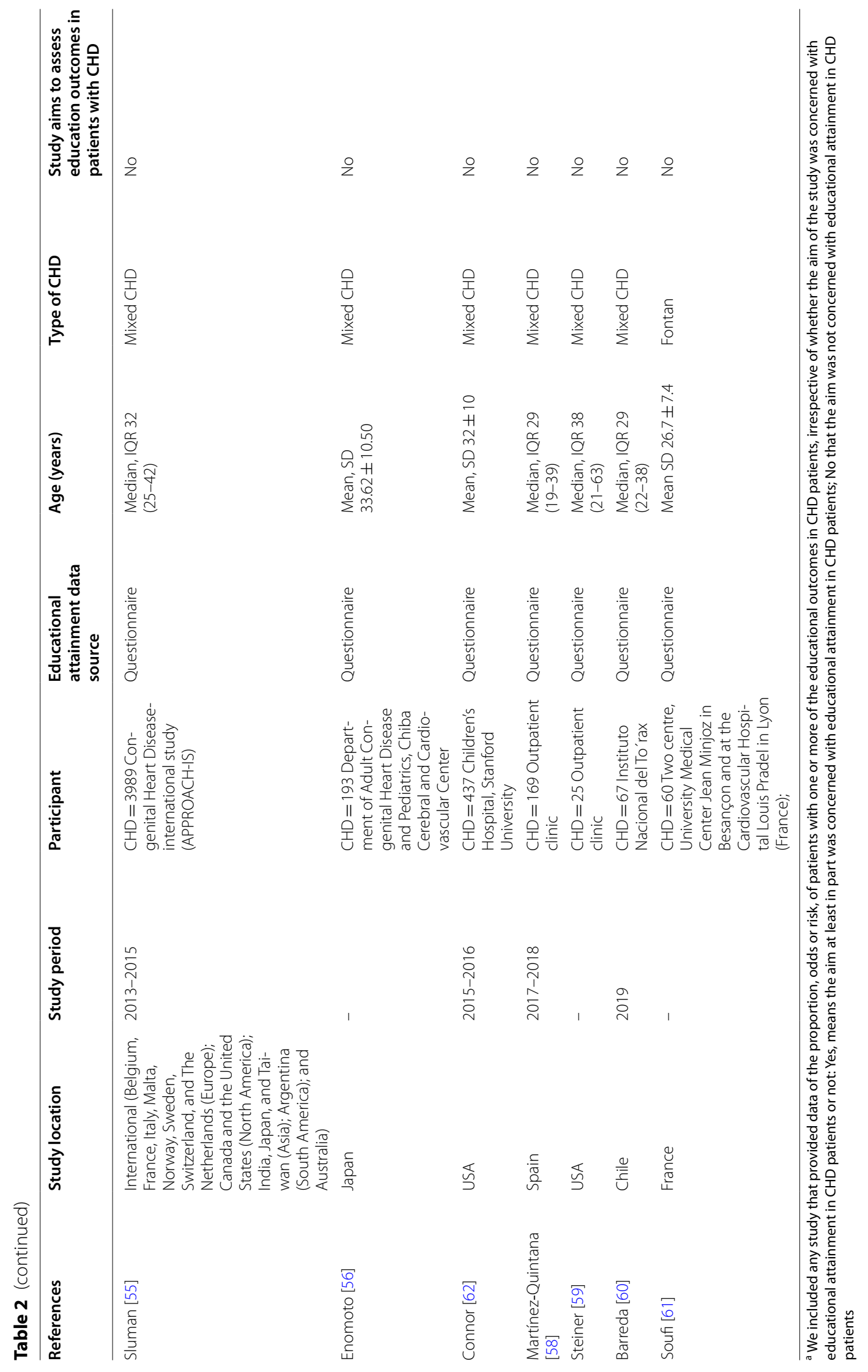


general population comparison group only in the main meta-analyses and in a sensitivity analysis repeated the meta-analysis with results comparing CHD patients to their siblings.

Educational attainment was evaluated with the same method in the two groups, with two [25, 27] exceptions, where information on the control group was obtained by published national statistics.

The number of patients with CHD ranged from 25 to 7019 across the studies. The unadjusted pooled analyses of the association of CHD with educational attainment included $11(\mathrm{~N}=104,585$ participants, 10,487 with CHD), 10 ( $\mathrm{N}=167,470$ participants, 11,820 with $\mathrm{CHD})$, and $8(\mathrm{~N}=150,813$ participants, 9817 with $\mathrm{CHD})$ for university degree, completing secondary education or vocational training, respectively. Equivalent studies for the age and sex adjusted analyses were $9(\mathrm{~N}=88,813$ participants, with $8880 \mathrm{CHD}), 7(\mathrm{~N}=101,429$ participants, 10,010 with $\mathrm{CHD})$, and 6 studies $(\mathrm{N}=100,544$ participants, 9614 with CHD) for university degree, completing secondary education or vocational training respectively.

Studies were carried out in Europe $(\mathrm{n}=21)$ [21, 22, 24-30, 32, 34, 36, 38, 39, 42, 43, 45, 54, 57, 58, 61], North America $(\mathrm{n}=11)$ [31, 33, 35, 40, 41, 47, 49, 52, 53, 59, 62], South America $(\mathrm{n}=1)$ [60], the Middle East $(\mathrm{n}=3)$ [23, 37, 44], Asia $(\mathrm{n}=4)[46,48,50,56]$, New Zealand $(\mathrm{n}=1)$ [51] and International $(n=1)$ [55]. Data on educational attainment were obtained by self-report questionnaires in the majority (39 (93\%)), with the remaining three obtaining this from linkage to national registers $[22,49,57]$.

\section{Comparison of educational attainment between CHD and non-CHD}

The pooled OR from studies comparing educational outcomes between those with and without CHD showed that patients with CHD had higher odds of not obtaining a university degree $(\mathrm{OR}=1.38,95 \% \mathrm{CI}[1.16,1.65])$ (Fig. 2a), not completing secondary education $(\mathrm{OR}=1.33$, 95\% CI $[1.09,1.61)$ (Fig. 2b) and not completing vocational training $(\mathrm{OR}=1.11,95 \% \mathrm{CI}[0.98-1.26])$ (Fig. 2c). For all three outcomes there was evidence of between study heterogeneity and the predictive interval for the odds ratios were 0.81 to $2.37,0.75$ to 2.33 , and 0.83 to 1.50 , for not obtaining a university degree, completing secondary education, and completing vocational training, respectively. Similar findings were found in an analysis restricted to the 8 studies that had controlled for sex and age and including the study with siblings as control group (Additional file 1: Fig. S2 and S3a-c).

Subgroup analyses did not suggest that between study heterogeneity was driven by differences in disease severity or year of publication (Table 3 ). There was some evidence that the increased odds of not obtaining a university degree or completing secondary education was more marked in studies from the Middle East compared to studies from Europe and North America, and that associations for these two outcomes were also stronger in women (Table 3). However, number of studies for subgroup analysis were limited. There was no strong evidence of publication bias (Additional file 1: Fig. S1a-c, Egger's $\mathrm{P}=0.74 ; 0.94 ; 0.50$ respectively for not obtaining a university degree, secondary education and vocational training).

The proportions with each educational outcome by country, in studies that did not report a peer non-CHD group, are compared to the summary data from 'Education at a Glance' in Table 4. For the majority, the proportions of each outcome in CHD patients were similar to the country level data for adults.

\section{Proportions of CHD patients with each educational outcome}

The pooled proportion of patients with CHD who completed a university degree, secondary education and vocational training was 36\% [95\% CI 30-43], 84\% [95\% CI 76-90] and 25\% [95\% CI 16-36] across all studies (Additional file 1: Fig. S4a-c). There was substantial between study heterogeneity and the predictive interval was 0.08 to 0.78 for obtaining a university degree, 0.23 to 0.99 for completing secondary education and 0.03 to 0.75 for completing vocational education.

\section{Risk of bias}

The item most identified at risk of bias was confounding, due to parental ethnicity, education, or age, as studies either controlled only for patient age and sex or nothing (Additional file 1: Table S2).

\section{Discussion}

The main finding of the present systematic review is that, despite patients and parents identifying educational attainment as a key concern, there is a paucity of research on the relationship of having a CHD and educational attainment. With an extensive search we identified only 12 studies with a comparison group of people without CHD, with only one adjusting for key confounders such as parental education, ethnicity, and age. Our meta-analysis of these studies showed a trend toward lower odds of completing a university degree, secondary education, or vocational training. However, given the sparsity of studies and between study heterogeneity the predictive intervals for all outcomes suggested educational attainment could be importantly lower or higher in those with CHD compared to their peers.

Despite havingcompiled all available published data since 1986 on university degree, secondary education, 


\begin{tabular}{|c|c|c|c|c|c|c|}
\hline \multirow{2}{*}{$\begin{array}{l}\text { a } \\
\text { Study }\end{array}$} & \multicolumn{3}{|c|}{ No-CHD } & CHD & \multirow{2}{*}{ Weight } & \multirow{2}{*}{$\begin{array}{c}\text { Odds Ratio } \\
\text { MH, Random, } 95 \% \mathrm{Cl}\end{array}$} \\
\hline & Events & Total & Events & Total & & \\
\hline Rose & 805 & 7355 & 22 & 111 & $7.4 \%$ & $0.50[0.31 ; 0.80]$ \\
\hline Caruana & 51 & 227 & 21 & 76 & $5.6 \%$ & $0.76[0.42 ; 1.37]$ \\
\hline Rometsch & 55 & 139 & 71 & 188 & $7.8 \%$ & $1.08[0.69 ; 1.69]$ \\
\hline Olsen & 2660 & 8554 & 207 & 770 & $14.2 \%$ & $1.23[1.04 ; 1.45]$ \\
\hline Simko & 87 & 124 & 76 & 124 & $6.5 \%$ & $1.49[0.88 ; 2.52]$ \\
\hline Zomer & 2704 & 6810 & 459 & 1496 & $15.1 \%$ & $1.49[1.32 ; 1.68]$ \\
\hline Madsen & 17889 & 68805 & 1333 & 7019 & $15.9 \%$ & $1.50[1.41 ; 1.59]$ \\
\hline Udholm & 528 & 1120 & 51 & 140 & $9.5 \%$ & $1.56[1.08 ; 2.24]$ \\
\hline Ozcan & 83 & 400 & 19 & 145 & $6.3 \%$ & $1.74[1.01 ; 2.98]$ \\
\hline Eslami & 164 & 353 & 84 & 347 & $10.4 \%$ & $2.72[1.97 ; 3.75]$ \\
\hline Kokkonen & 36 & 211 & 2 & 71 & $1.3 \%$ & $7.10[1.66 ; 30.28]$ \\
\hline $\begin{array}{l}\text { Total }(95 \% \text { C } \\
\text { Prediction ir } \\
\text { Heterogeneity }\end{array}$ & $\begin{array}{l}\text { val } \\
u^{2}=0\end{array}$ & 94098 & $2=$ & 10487 & $100.0 \%$ & $\begin{array}{c}1.38[1.16 ; 1.65] \\
{[0.81 ; 2.37]} \\
;\left.\right|^{2}=80 \%\end{array}$ \\
\hline
\end{tabular}

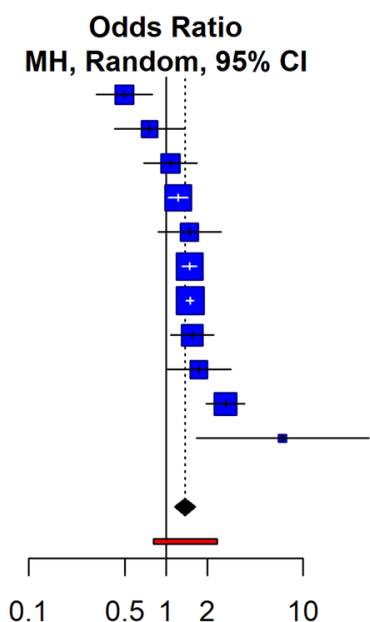

Favours CHD patients $<==>$ Favours those without $\mathrm{CHD}$ Not achieving university degree

b

Study

Rose

Simko

Zomer

Caruana

Shaefer

Olsen

Madsen

Eslami

Rometsch

Udholm

\begin{tabular}{rr}
\multicolumn{2}{c}{ No-CHD } \\
Events & Total Ev \\
1545 & 7355 \\
122 & 124 \\
4753 & 6810 \\
196 & 347 \\
47679 & 50066 \\
13837 & 20531 \\
22018 & 68805 \\
290 & 353 \\
139 & 139 \\
1120 & 1120
\end{tabular}

155650

Total $(95 \% \mathrm{Cl})$

Prediction interval

Heterogeneity: $\mathrm{Tau}^{2}=0.0500 ; \mathrm{Chi}^{2}=65.98, \mathrm{df}=9(\mathrm{P}<0.01) ; \mathrm{I}^{2}=86 \%$

CHD

Odds Ratio

$111 \quad 10.8 \% \quad 0.58[0.39 ; \quad 0.87]$

$124 \quad 0.9 \% \quad 1.00[0.14 ; \quad 7.21]$

$1496 \quad 18.6 \% \quad 1.07[0.94 ; \quad 1.20]$

$120 \quad 10.5 \% \quad 1.21[0.80 ; \quad 1.84]$

$203 \quad 7.5 \% \quad 1.37[0.78 ; \quad 2.40]$

$2072 \quad 19.1 \% \quad 1.51[1.38 ; 1.65]$

$\begin{array}{lllll}614 & 7019 & 19.6 \% & 1.58[1.49 ; & 1.67]\end{array}$

$237 \quad 347 \quad 12.1 \% \quad 2.14[1.50 ; \quad 3.04]$

$184 \quad 188 \quad 0.4 \% \quad 6.80[0.36 ; 127.44]$

$137 \quad 140 \quad 0.4 \% \quad 57.04[2.93 ; 1110.20]$

$3[1.09 ; 1.61]$

$0.75 ; 2.33]$

Favours $\mathrm{CHD}$ patients $<=\Rightarrow$ Favours those without $\mathrm{CHD}$

Not achieving secondary education

C

Study

Simko

Rometsch

Olsen

Madsen

Kokkonen

Shaefer

Udholm

\begin{tabular}{rr}
\multicolumn{2}{c}{ No-CHD } \\
Events & Total Ev \\
6 & 124 \\
68 & 139 \\
5071 & 20531 \\
6881 & 68805 \\
151 & 211 \\
39336 & 50066 \\
433 & 1120
\end{tabular}

140996

Total $(95 \% \mathrm{Cl})$

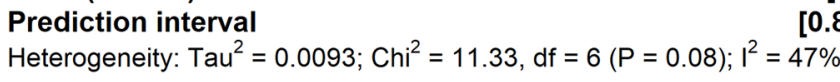

Odds Ratio

CHD

ents Total Weight MH, Random, $95 \% \mathrm{C}$

$\begin{array}{lll}12 & 124 \quad 1.4 \%\end{array}$

\begin{tabular}{lll}
$93 \quad 188 \quad 6.6 \%$ \\
\hline
\end{tabular}

$4992072 \quad 32.3 \%$

$6747019 \quad 35.5 \%$

$\begin{array}{lll}46 & 71 & 4.2 \%\end{array}$

$146 \quad 203 \quad 11.7 \%$

$40 \quad 140 \quad 8.2 \%$
$0.47[0.17 ; 1.31]$

$0.98[0.63 ; 1.52]$

$1.03[0.93 ; 1.15]$

$1.05[0.96 ; 1.14]$

$1.37[0.77 ; 2.42]$

$1.43[1.05 ; 1.95]$

$1.58[1.07 ; 2.32]$

$1.11[0.98 ; 1.26]$

$[0.83 ; 1.50]$

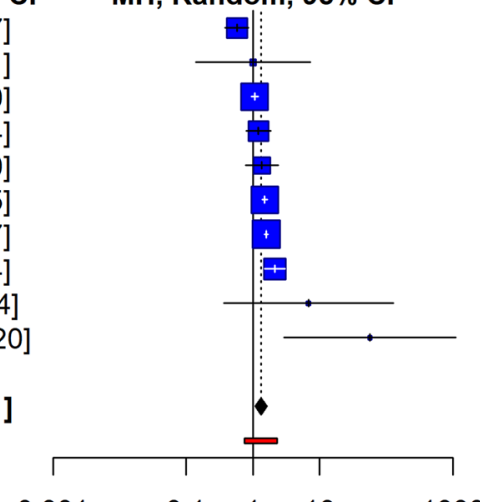

Odds Ratio

$\mathrm{MH}$, Random, $95 \% \mathrm{Cl}$ 
Table 3 Subgroup analyses for association between CHD and educational attainment

\begin{tabular}{|c|c|c|c|}
\hline Subgroup & $\begin{array}{l}\text { Number of studies ( } \mathrm{n} \text { CHD cases, } \mathrm{n} \\
\text { non-CHD) }\end{array}$ & $\begin{array}{l}\text { OR }(95 \% \mathrm{Cl}) \text { for not achieving educational } \\
\text { outcome per subgroup }\end{array}$ & $\begin{array}{l}\text { Test for subgroup } \\
\text { differences } \mathrm{p} \text { value }\end{array}$ \\
\hline \multicolumn{4}{|c|}{ Not obtaining a university degree } \\
\hline \multicolumn{4}{|c|}{ Geographic area } \\
\hline Europe & 8 (9871 vs. 93,221) & $1.24[1.03 ; 1.49]$ & \multirow[t]{3}{*}{0.03} \\
\hline North America & 1 (124 vs. 124) & $1.49[0.88 ; 2.52]$ & \\
\hline Middle East & 2 (492 vs. 753 ) & $2.29[1.50 ; 3.51]$ & \\
\hline \multicolumn{4}{|l|}{ Year of the study } \\
\hline Before 2015 & 7 (3064 vs. 23,807) & $1.47[1.08 ; 2.02]$ & \multirow[t]{2}{*}{0.55} \\
\hline 2015 and after & 4 (7423 vs. 70,291) & $1.30[1.01 ; 1.67]$ & \\
\hline \multicolumn{4}{|c|}{ Proportion of females } \\
\hline$\geq 50 \%$ & 4 (7630 vs. 70,402) & $1.75[1.30 ; 2.35$ & \multirow[t]{2}{*}{0.14} \\
\hline$<50 \%$ & 6 (2087 vs. 15,142) & $1.17[0.75 ; 1.84]$ & \\
\hline \multicolumn{4}{|c|}{ Proportion of severe disease } \\
\hline$\geq 10 \%$ & 6 (2376 vs. 8053) & $1.49[1.10 ; 2.02]$ & \multirow[t]{2}{*}{0.43} \\
\hline$<10 \%$ & 5 (8111 vs. 86,045) & $1.25[0.93 ; 1.69]$ & \\
\hline \multicolumn{4}{|c|}{ Not completing secondary education } \\
\hline \multicolumn{4}{|c|}{ Geographic area } \\
\hline Europe & $8(11,349$ vs. 155,173$)$ & $1.24[1.01 ; 1.53]$ & \multirow{3}{*}{0.03} \\
\hline North America & 1 (124 vs. 124) & $1.00[0.14 ; 7.21]$ & \\
\hline Middle East & 1 (347 vs. 353) & $2.14[1.50 ; 3.04]$ & \\
\hline \multicolumn{4}{|l|}{ Year of the study } \\
\hline Before 2015 & 5 (4150 vs. 35,173$)$ & $1.21[0.87 ; 1.67]$ & \multirow[t]{2}{*}{0.34} \\
\hline 2015 and after & 5 (7670 vs. 120,477) & $1.52[1.08 ; 2.14]$ & \\
\hline \multicolumn{4}{|c|}{ Proportion of females } \\
\hline$\geq 50 \%$ & 4 (7630 vs. 70,402) & $1.88[1.22 ; 2.89]$ & \multirow[t]{2}{*}{0.04} \\
\hline$<50 \%$ & 5 (2118 vs. 64,717) & $1.01[0.74 ; 1.40]$ & \\
\hline \multicolumn{4}{|c|}{ Proportion of severe disease } \\
\hline$\geq 10 \%$ & 6 (2478 vs. 57,839$)$ & $1.39[0.99 ; 1.94]$ & \multirow[t]{2}{*}{0.77} \\
\hline$<10 \%$ & 4 (9342 vs. 97,811) & $1.30[1.02 ; 1.67]$ & \\
\hline \multicolumn{4}{|c|}{ Not completing vocational training } \\
\hline \multicolumn{4}{|c|}{ Geographic area } \\
\hline Europe & 6 (9693 vs. 140,872) & $1.12[1.00 ; 1.25]$ & \multirow{3}{*}{0.10} \\
\hline North America & 1 (124 vs. 124) & $0.47[0.17 ; 1.31]$ & \\
\hline Middle East & - & - & \\
\hline \multicolumn{4}{|l|}{ Year of the study } \\
\hline Before 2015 & 3 (2267 vs. 20,866) & $1.03[0.74 ; 1.43]$ & \multirow[t]{2}{*}{0.43} \\
\hline 2015 and after & 4 (7550 vs. 120,130) & $1.20[0.96 ; 1.51]$ & \\
\hline \multicolumn{4}{|c|}{ Proportion of females } \\
\hline$\geq 50 \%$ & 3 (7283 vs. 70,049) & $1.10[0.73 ; 1.65]$ & \multirow[t]{2}{*}{0.52} \\
\hline$<50 \%$ & 3 (462 vs. 50,416$)$ & $1.28[1.02 ; 1.61]$ & \\
\hline \multicolumn{4}{|c|}{ Proportion of severe disease } \\
\hline$\geq 10 \%$ & 3 (515 vs. 50,329) & $1.04[0.65 ; 1.67]$ & 0.87 \\
\hline$<10 \%$ & 4 (9302 vs. 90,667) & $1.08[0.97 ; 1.20]$ & \\
\hline
\end{tabular}

and vocational training in CHD patients, we found a very limited number of studies addressing this subject. Pooling evidence from studies that included a control group we found that patients with CHD were at higher odds of not completing university, secondary and vocational educational levels compared to non-CHD peers. There was evidence that this gap was more pronounced in studies from the Middle East compared to those from Europe and North America. It is likely that different educational systems might have a different impact on educational 
Table 4 Educational attainment for adult (>18 years) CHD patients compared to educational attainment in all adults (25-64-year) from the same country as the CHD patients using data from 'Education at a Glance'

\begin{tabular}{|c|c|c|c|c|c|c|c|}
\hline \multirow[t]{2}{*}{ References } & \multirow[t]{2}{*}{ Country } & \multicolumn{3}{|l|}{ CHD patients } & \multicolumn{3}{|c|}{ Whole country } \\
\hline & & $\begin{array}{l}\text { University } \\
\text { degree } \% \text {, [95\% } \\
\mathrm{Cl}]\end{array}$ & $\begin{array}{l}\text { Secondary } \\
\text { education \%, } \\
{[95 \% \mathrm{Cl}]}\end{array}$ & $\begin{array}{l}\text { Vocational } \\
\text { training \%, [95\% } \\
\mathrm{Cl}]\end{array}$ & $\begin{array}{l}\text { University } \\
\text { degree }(\%)\end{array}$ & $\begin{array}{l}\text { Secondary } \\
\text { education (\%) }\end{array}$ & $\begin{array}{l}\text { Vocational } \\
\text { education } \\
(\%)\end{array}$ \\
\hline Ternestedt [42] & Sweden & 27 [12-48] & 81 [61-93] & & 32 & 81 & \\
\hline Nieminen [28] & Finland & $10[9-11]$ & 78 [77-80] & & 34 & 76 & \\
\hline Moons [43] & Belgium & $42[38-46]$ & 98 [96-99] & 35 [31-39] & 33 & 70 & 2 \\
\hline Kovacs [41] & Canada/US & 61 [55-67] & & & 41 & 89 & \\
\hline Riley [16] & United Kingdom & 58 [47-67] & & & 38 & 75 & \\
\hline Ozcan [23] & Turkey & 13 [8-20] & & & 14 & 32 & \\
\hline Bygstad [29] & Denmark & 31 [21-41] & 68 [58-78] & 27 [19-37] & 34 & 77 & \\
\hline Pike [47] & US & $61[47-74]$ & & & 42 & 89 & \\
\hline Bang [467] & South Korea & 85 [75-92] & 95 [88-99] & & 41 & 82 & \\
\hline Opic [39] & Netherland & 27 [22-33] & 74 [68-79] & & 36 & 77 & 0 \\
\hline Karsenty [34] & France & & 38 [30-47] & & 34 & 78 & 0 \\
\hline Eren [44] & Turkey & 19 [10-30] & $54[41-66]$ & & 46 & 91 & \\
\hline O'Donovan [51] & New Zealand & 26 [18-36] & & & 42 & 78 & \\
\hline Tumin [49] & US & $51[46-56]$ & & & 47 & 91 & \\
\hline Schiele [53] & US & 36 [29-44] & & & 48 & 91 & \\
\hline Fedchenko [54] & Sweden & 50 [38-62] & 93 [85-98] & 12 [6-22] & 43.3 & 83.2 & 7.4 \\
\hline Pfitzer [32] & Germany & & $46[42-49]$ & & 29.1 & 86.7 & 12.2 \\
\hline Enomoto [56] & Japan & $58[51-65]$ & & & 52 & 100 & \\
\hline Connor [62] & US & 50 [46-44] & 100 [99-100] & & 47.4 & 90.8 & 0.4 \\
\hline Gleason [52] & US & 59 [50-68] & 100 [97-100] & $6[4-8]$ & 47.4 & 90.8 & \\
\hline
\end{tabular}

Education at a Glance population sample size not reported; data are presented in broad age groups and the $25-64$ year old group was the one that matched best with the main age of participants across our studies

attainment among children with CHD. These aspects may include curricula, methods of teaching, access to teaching material, and the quality and extent of special educational support offered to children who might have reduced school attendance due to repeat treatments. Studies included in the present meta-analysis did not report information on educational support. However, a previous report has shown that in North America children with CHD are more likely to receive additional educational support compared with their peers [63]. We also found some evidence that the gap in education attainment may be more pronounced in females. This could possibly reflect the fact that in general girls do better in school than boys, and additional needs may therefore be less apparent in girls with CHD. However, it is important to note that we have limited statistical power for any of our subgroup analyses.

It has been hypothesised that children with CHD may be exposed to neurotoxic factors which can affect brain development, such as cyanosis, neurotoxicity related to the use of cardiopulmonary bypass, and hypothermic circulatory arrest in children undergoing heart surgery ration [64]. These concerns have prompted recent improvements in surgical techniques and patient management, including the adoption of neuroprotective strategies [65]. The extent to which these would redress the lower educational attainment in patients with CHD is as yet unknown. It is also possible that chromosomal abnormalities commonly associated with CHD, such as Down's syndrome, contribute to lower educational attainment in CHD patients [66]. It was not possible to determine the extent to which these abnormalities explained the results of our systematic review and it would be useful for future studies to attempt to explore this, for example, by stratifying results by chromosomal abnormality and/or undertaking sensitivity analyses with this group removed. Chromosomal abnormalities may be related to more severe $\mathrm{CHD}$ and the odds ratios for not attaining different educational outcomes were higher in the subgroup of studies including more severe CHD patients, but we had limited power to detect differences between the two subgroups based on severity.

The incidence of psychological and psychiatric disorders such as inattention and hyperactivity have been reported to be high in CHD patients [67] and these conditions affect academic performance [68]. Again this 
was not explored in studies that we identified for this review. Finally, patients with CHD are likely to experience recurrent chest infection [69, 70], endocarditis, cardiac arrhythmias [71] or repeated surgeries with frequent and prolonged absence from the school. However, the studies we identified and reviewed did not explore whether associations were mediated by school absence. Whilst some studies selected people without CHD from general population registers, others recruited from peers or friends of the CHD patients or their families, through media adverts or people with other disorders. One recent large record-linkage study that aimed to compare attainment of self-sufficiency and other outcomes, including educational attainment, among CHD patients and those without CHD undertook within sibling and general population analyses [57]. In our main analyses we pooled results from the general population comparison group (consistent with other studies included in the meta-analysis) but we also repeated the analysis with the odds of each education outcome in CHD patients versus their siblings, and we found very similar results to the general population comparison. Within sibling comparisons such as this are able to control for unobserved fixed family confounding, such as parental ethnicity, socioeconomic position and education [72]. Thus, these findings provide some support that the overall meta-analysis results may not be majorly affected by key family confounding but as this is one single study the potential for residual confounding to have influenced our findings should still be considered.

There were differences between findings from metaanalyses of the 12 studies that had included a comparison group and those studies combined with an additional 30 that only included adults with CHD. In the studies with a non-CHD comparison group we found evidence of lower educational attainment in CHD patients, though with substantial between study heterogeneity. By contrast, when we compared the proportion of educational attainment in CHD patients reported by studies included with data in the national population from Educational at glance when available, we did not find any strong differences. The latter results are limited by lack of adjustment for any potential confounders, and the inclusion of the whole national population in the comparison group, including those with CHDs. Furthermore, whilst we tried to match the year of data collection in the CHD study as close as possible to the year of national data collection, differences in education policy and provision over time may have impacted results, which may have contributed to similar results between the two groups.

A key result of our review is to highlight the paucity of high quality research in this area. On the basis of evidence from studies that have included a non-CHD comparison group we would suggest that training programmes for school personnel and additional educational support for students with CHD should be considered.

\section{Strengths and limitations}

The key strength of this study is our attempt, for the first time, to obtain and review all relevant data, including studies where the aim was to assess the association of having a CHD with educational attainment and those where this was not the aim. We acknowledge for the latter that our search strategy may have missed some studies where a description of educational attainment in patients with CHD was somewhere in the paper. We have presented predictive intervals, as well as odds ratios and confidence intervals, which are recommended when undertaking random effects meta-analyses because of assumed between study heterogeneity, but rarely undertaken [16, 73]. We attempted to standardize academic levels achieved whilst focusing on key measures that are related to future employment, socioeconomic position and health (university, secondary and vocational training). However, we acknowledge that across different educational systems the level of knowledge and skills required is likely to vary. Our results are limited by the sparsity of studies and the lack of any studies that have controlled for key confounding factors.

\section{Challenges of undertaking research in this area and some possible opportunities}

Research in this area is affected by the rarity of the conditions, which limits the possibility to undertake a robust analyses within the single birth cohorts. On the other hand, linkage between educational and health data has not been systematically performed across all countries. Despite recent advances in multidimensional data repositories, which may facilitate research in this area, large registries are unlikely to allow discrimination between the large spectrum of different types of $\mathrm{CHD}$ and their different impact on neurological development and educational attainment. Large birth cohort collaborations such as LifeCycle [74] can potentially offer the advantage of achieving a larger sample of patients with CHD [12] with granular longitudinal data and the possibility to investigate variability related to different countries and educational systems.

\section{Conclusions}

In conclusion, in the present systematic review and meta-analysis we appraised current literature on educational attainment in patients with CHD. We found that there is a limited number of studies addressing this topic and the majority of them are limited by lack of comparison group and adjustment for key confounding 
factors. Bearing in mind these limitations, our analysis showed some evidence of lower educational attainment in CHD patients. Further studies are of paramount importance, with large collaborations across birth cohorts being one potential mechanism for improving research in this area.

\section{Abbreviation}

CHD: Congenital heart disease.

\section{Supplementary Information}

The online version contains supplementary material available at https://doi. org/10.1186/s12872-021-02349-z.

Additional file 1: Supplementary material.

\section{Acknowledgements}

Not applicable.

\section{Authors' contributions}

The corresponding author attests that all listed authors meet authorship criteria and that no others meeting the criteria have been omitted. LC: Planning, conduct, and reporting of the work described in the article, and being responsible for the overall content as guarantor. AD: Conduct and reporting of the work described in the article. GB: Conduct and reporting of the work described in the article. RC: Planning, conduct, and reporting of the work described in the article. MC: Reporting of the work described in the article. DL: Planning, conduct, and reporting of the work described in the article, and being responsible for the overall content as guarantor. The Corresponding Author has the right to grant on behalf of all authors and does grant on behalf of all authors, a worldwide licence to the Publishers and its licensees in perpetuity, in all forms, formats and media (whether known now or created in the future), to (i) publish, reproduce, distribute, display and store the Contribution, (ii) translate the Contribution into other languages, create adaptations, reprints, include within collections and create summaries, extracts and/or, abstracts of the Contribution, (iii) create any other derivative work(s) based on the Contribution, (iv) to exploit all subsidiary rights in the Contribution, (v) the inclusion of electronic links from the Contribution to third party material where-ever it may be located; and, (vi) licence any third party to do any or all of the above. Lucia Cocomello: This author takes responsibility for all aspects of the reliability and freedom from bias of the data presented and their discussed interpretation. Deborah A. Lawlor: This author takes responsibility for all aspects of the reliability and freedom from bias of the data presented and their discussed interpretation. All authors read and approved the final manuscript

\section{Funding}

This work was supported by the British Heart Foundation Accelerator Award (AA/18/7/34219), which funds LC, and the Bristol National Institute of Health Research Biomedical Research Centre. LC, RC, and DAL work in a unit that receives support from the University of Bristol and the UK Medical Research Council (MC_UU_00011/6). DAL is supported by the BHF Chair in Cardiovascular Science and Clinical Epidemiology (CH/F/20/90003) and a National Institute of Health Research Senior Investigator (NF-0616-10102). MC is supported by the British Heart Foundation Chair in Congenital Heart Disease $(\mathrm{CH} / 1 / 32804)$. The views expressed in this publication are those of the author(s) and not necessarily those of the UK National Health Service, the National Institute for Health Research or the UK Department of Health and Social Care, or any other funders mentioned here.

\section{Availability of data and materials}

All data generated or analysed during this study are included in this published article and its supplementary information files.

\section{Declarations}

Ethics approval and consent to participate

Not applicable.

\section{Consent for publication}

Not applicable.

\section{Competing interests}

All authors have completed the ICMJE uniform disclosure form at www.icmje. org/coi_disclosure.pdf and declare the following. DAL has received funding from Wellcome, the European Research Council (ERC Advanced grant and a Horizon 2020 grant), US National Institute of Health, Diabetes UK, Roche Diagnostics and Medtronic Ltd for research unrelated to that presented here. MC has received funding from Medtronic Ltd for research unrelated to that presented. All other authors report no financial relationships with any organisations that might have an interest in the submitted work in the previous three years; no other relationships or activities that could appear to have influenced the submitted work.

\section{Author details}

${ }^{1} \mathrm{MRC}$ Integrative Epidemiology Unit, Oakfield House, Oakfield Grove, Bristol BS8 2BN, UK. ${ }^{2}$ Bristol Heart Institute, Terrell St, Bristol BS2 8 ED, UK. ${ }^{3}$ Bristol Medical School, Tyndall Avenue, Bristol BS8 1UD, UK. ${ }^{4}$ National Heart and Lung Institute, Imperial College London, London, UK. ${ }^{5}$ Population Health Sciences, Bristol Medical School, University of Bristol, Bristol, UK. ${ }^{6}$ Bristol NIHR Biomedical Research Centre, Bristol, UK.

Received: 16 June 2021 Accepted: 18 October 2021

Published online: 19 November 2021

\section{References}

1. Bernier PLSA, Samoukovic G, Tchervenkov CI. The challenge of congenital heart disease worldwide: epidemiologic and demographic facts. Semin Thorac Cardiovasc Surg Pediatr Card Surg Annu. 2010;13:26-34.

2. Gilboa SMSJ, Nembhard WN, Fixler DE, Correa A. Mortality resulting from congenital heart disease among children and adults in the United States, 1999 to 2006. Circulation. 2010;122:2254-63.

3. Marelli AJMA, lonescu-Ittu R, Rahme E, Pilote L. Congenital heart disease in the general population: changing prevalence and age distribution. Circulation. 2007;115:163-72.

4. Pandya B, Cullen S, Walker F. Congenital heart disease in adults. BMJ. 2016;354:i3905.

5. Ladouceur M, Iserin L, Cohen S, Legendre A, Boudjemline Y, Bonnet D. Key issues of daily life in adults with congenital heart disease. Arch Cardiovasc Dis. 2013;106(6-7):404-12.

6. Hummer RA, Hernandez EM. The effect of educational attainment on adult mortality in the United States. Popul Bull. 2013;68(1):1-16.

7. Davies NM, Dickson M, Davey Smith G, van den Berg GJ, Windmeijer F. The causal effects of education on health outcomes in the UK Biobank. Nat Hum Behav. 2018;2(2):117-25.

8. Carter AR, Gill D, Davies NM, Taylor AE, Tillmann T, Vaucher J, et al. Understanding the consequences of education inequality on cardiovascular disease: Mendelian randomisation study. BMJ. 2019;365:11855.

9. Gerstle M, Beebe DW, Drotar D, Cassedy A, Marino BS. Executive functioning and school performance among pediatric survivors of complex congenital heart disease. J Pediatr. 2016;173:154-9.

10. Stroup DF, Berlin JA, Morton SC, Olkin I, Williamson GD, Rennie D, et al. Meta-analysis of observational studies in epidemiology: a proposal for reporting. Meta-analysis Of Observational Studies in Epidemiology (MOOSE) group. JAMA. 2000;283(15):2008-12.

11. Pearce N, Lawlor DA. Causal inference-so much more than statistics. Int J Epidemiol. 2016;45(6):1895-903.

12. Taylor K, Elhakeem A, Nader JLT, Yang T, Isaevska E, Richiardi L, et al. The effect of maternal pre-/early-pregnancy BMI and pregnancy smoking and alcohol on congenital heart diseases: a parental negative control study. medRxiv. 2020;6:66.

13. OECD. Available from: https://www.oecd.org/. 
14. Morgan RL, Thayer KA, Santesso N, Holloway AC, Blain R, Eftim SE, et al A risk of bias instrument for non-randomized studies of exposures: a users' guide to its application in the context of GRADE. Environ Int 2019;122:168-84.

15. Higgins JP, Thompson SG, Spiegelhalter DJ. A re-evaluation of randomeffects meta-analysis. J R Stat Soc Ser A Stat Soc. 2009;172(1):137-59.

16. Riley RD, Higgins JP, Deeks JJ. Interpretation of random effects metaanalyses. BMJ. 2011;342:549.

17. Glance Eaa. https://www.oecd-ilibrary.org/education/education-at-aglance-2020_69096873-en.

18. Matter LH. Ihm.

19. Matter LH. transition secondary. https://www.Ihm.org.uk/information/ lifestyle-information/education/transition-secondary-school/.

20. Matter LH. University. https://www.Ihm.org.uk/information/lifestyle-infor mation/education/guide-to-university-when-you-have-a-single-ventr icle-heart-condition/.

21. Kokkonen J, Paavilainen T. Social adaptation of young adults with congenital heart disease. Int J Cardiol. 1992;36(1):23-9.

22. Olsen M, Hjortdal VE, Mortensen LH, Christensen TD, Sørensen HT, Pedersen L. Educational achievement among long-term survivors of congenital heart defects: a Danish population-based follow-up study. Cardiol Young. 2011;21(2):197-203.

23. Ozcan EE, Alaattin K. Impact of congenital heart disease on higher education. Circulation. 2010;122(2):e207.

24. Zomer AC, Vaartjes I, Uiterwaal CS, van der Velde ET, Sieswerda GJ, Wajon EM, et al. Social burden and lifestyle in adults with congenital heart disease. Am J Cardiol. 2012;109(11):1657-63.

25. Maryanne Caruana VG. Congenital heart disease has no negative impact on educational achievements and employment among maltese adult patients under clinical follow-up. Int Cardiovasc Forum J. 2016;6:8.

26. Udholm S, Nyboe C, Dantoft TM, Jørgensen T, Rask CU, Hjortdal VE. Small atrial septal defects are associated with psychiatric diagnoses, emotional distress, and lower educational levels. Congenit Heart Dis. 2019;14(5):803-10.

27. Schaefer CJ, Hoop R, Schürch-Reith S, Stambach D, Kretschmar O, Bauersfeld $U$, et al. Academic achievement and satisfaction in adolescents with CHD. Cardiol Young. 2016;26(2):257-62.

28. Nieminen $H$, Sairanen $H$, Tikanoja T, Leskinen $M$, Ekblad H, Galambosi $P_{\text {, }}$ et al. Long-term results of pediatric cardiac surgery in Finland: education, employment, marital status, and parenthood. Pediatrics. 2003;112(6 Pt 1):1345-50

29. Bygstad E, Pedersen LC, Pedersen TA, Hjortdal VE. Tetralogy of Fallot in men: quality of life, family, education, and employment. Cardiol Young. 2012;22(4):417-23.

30. Otterstad JE, Tjore I, Sundby P. Social function of adults with isolated ventricular septal defects. Possible negative effects of surgical repair? Scand J Soc Med. 1986;14(1):15-23.

31. Lillehei CW, Varco RL, Cohen M, Warden HE, Gott VL, DeWall RA, et al. The first open heart corrections of tetralogy of Fallot. A 26-31 year follow-up of 106 patients. Ann Surg. 1986;204(4):490-502.

32. Pfitzer C, Helm PC, Rosenthal LM, Walker C, Ferentzi H, Bauer UMM, et al. Educational level and employment status in adults with congenital heart disease. Cardiol Young. 2018:28(1):32-8.

33. Moller JH, Patton C, Varco RL, Lillehei CW. Late results (30 to 35 years) after operative closure of isolated ventricular septal defect from 1954 to 1960. Am J Cardiol. 1991;68(15):1491-7.

34. Karsenty C, Hascoet S, Blot-Souletie N, Galinier M, Maury P, Mondoly P, et al. The medical past of adults with complex congenital heart disease impacts their social development and professional activity. Arch Cardiovasc Dis. 2013;106(8-9):469-70.

35. Simko LC, MCGinnis KA. Quality of life experienced by adults with congenital heart disease. AACN Clin Issues. 2003;14(1):42-53.

36. Rose M, Köhler K, Köhler F, Sawitzky B, Fliege H, Klapp BF. Determinants of the quality of life of patients with congenital heart disease. Qual Life Res. 2005; 14(1):35-43.

37. Eslami B, Sundin O, Macassa G, Khankeh HR, Soares JJ. Anxiety, depressive and somatic symptoms in adults with congenital heart disease. J Psychosom Res. 2013;74(1):49-56.

38. Rometsch S, Greutmann M, Latal B, Bernaschina I, Knirsch W, Schaefer C, et al. Predictors of quality of life in young adults with congenital heart disease. Eur Heart J Qual Care Clin Outcomes. 2019:5(2):161-8.
39. Opić P, Roos-Hesselink JW, Cuypers JA, Witsenburg M, van den Bosch A, van Domburg RT, et al. Psychosocial functioning of adults with congenital heart disease: outcomes of a 30-43 year longitudinal follow-up. Clin Res Cardiol. 2015;104(5):388-400.

40. Brandhagen DJ, Feldt RH, Williams DE. Long-term psychologic implications of congenital heart disease: a 25-year follow-up. Mayo Clin Proc. 1991;66(5):474-9.

41. Kovacs AH, Saidi AS, Kuhl EA, Sears SF, Silversides C, Harrison JL, et al. Depression and anxiety in adult congenital heart disease: predictors and prevalence. Int J Cardiol. 2009;137(2):158-64.

42. Ternestedt BM, Wall K, Oddsson H, Riesenfeld T, Groth I, Schollin J. Quality of life 20 and 30 years after surgery in patients operated on for tetralogy of Fallot and for atrial septal defect. Pediatr Cardiol. 2001;22(2):128-32.

43. Moons P, Van Deyk K, Marquet K, De Bleser L, De Geest S, Budts W. Profile of adults with congenital heart disease having a good, moderate, or poor quality of life: a cluster analytic study. Eur J Cardiovasc Nurs. 2009;8(2):151-7.

44. Eren NK, Kırdök AH, Kılıçaslan B, Kocabaş U, Düzel B, Berilgen R, et al. Quality of life of patients with atrial septal defect following percutaneous closure. Cardiol Young. 2015;25(1):42-6.

45. Riley JP, Habibi H, Banya W, Gatzoulis MA, Lau-Walker M, Cowie MR. Education and support needs of the older adult with congenital heart disease. J Adv Nurs. 2012;68(5):1050-60.

46. Bang JS, Jo S, Kim GB, Kwon BS, Bae EJ, Noh Cl, et al. The mental health and quality of life of adult patients with congenital heart disease. Int J Cardiol. 2013;170(1):49-53.

47. Pike NA, Evangelista LS, Doering LV, Eastwood JA, Lewis AB, Child JS. Quality of life, health status, and depression: comparison between adolescents and adults after the Fontan procedure with healthy counterparts. J Cardiovasc Nurs. 2012;27(6):539-46.

48. Chen CA, Liao SC, Wang JK, Chang Cl, Chiu IS, Chen YS, et al. Quality of life in adults with congenital heart disease: biopsychosocial determinants and sex-related differences. Heart. 2011;97(1):38-43.

49. Tumin D, Chou H, Hayes D, Tobias JD, Galantowicz M, McConnell PI. Employment after heart transplantation among adults with congenital heart disease. Congenit Heart Dis. 2017;12(6):794-9.

50. Aherrera JAM, Abrahan LL, Racaza GZ, Train CQ, Jara RD. Depression and anxiety in adults with congenital heart disease using the validated filipino version of the hospital anxiety and depression score (HADS-P). Phillip J Intern Med. 2016;54(1):66.

51. O'Donovan CE, Painter L, Lowe B, Robinson H, Broadbent E. The impact of illness perceptions and disease severity on quality of life in congenital heart disease. Cardiol Young. 2016;26(1):100-9.

52. Gleason LP, Deng LX, Khan AM, Drajpuch D, Fuller S, Ludmir J, et al. Psychological distress in adults with congenital heart disease: focus beyond depression. Cardiol Young. 2019;29(2):185-9.

53. Schiele SE, Emery CF, Jackson JL. The role of illness uncertainty in the relationship between disease knowledge and patient-reported outcomes among adolescents and adults with congenital heart disease. Heart Lung. 2019;48(4):325-30.

54. Fedchenko M, Mandalenakis Z, Dellborg H, Hultsberg-Olsson G, Bjork A Eriksson $\mathrm{P}$, et al. Cardiovascular risk factors in adults with coarctation of the aorta. Congenit Heart Dis. 2019;14(4):549-58.

55. Sluman MA, Apers S, Sluiter JK, Nieuwenhuijsen K, Moons P, Luyckx K, et al. Education as important predictor for successful employment in adults with congenital heart disease worldwide. Congenit Heart Dis. 2019;14(3):362-71.

56. Enomoto J, Mizuno Y, Okajima Y, Kawasoe Y, Morishima H, Tateno S. Employment status and contributing factors among adults with congenital heart disease in Japan. Pediatr Int. 2020;62(3):390-8.

57. Madsen NL, Marino BS, Woo JG, Olsen M. Comparison of economic selfsufficiency and educational attainment in adults with congenital heart disease versus siblings without heart disease and to general population. Am J Cardiol. 2020;135:135-42.

58. Martinez-Quintana E, Girolimetti A, Jimenez-Rodriguez S, FraguelaMedina C, Rodriguez-Gonzalez F, Tugores A. Prevalence and predictors of psychological distress in congenital heart disease patients. J Clin Psychol. 2020;76(9):1705-18

59. Steiner JM, Dhami A, Brown CE, Stout KK, Curtis JR, Engelberg RA, et al. Barriers and facilitators of palliative care and advance care planning in adults with congenital heart disease. Am J Cardiol. 2020;135:128-34. 
60. Lopez Barreda R, Guerrero A, de la Cuadra JC, Scotoni M, Salas W, Baraona $F$, et al. Poverty, quality of life and psychological wellbeing in adults with congenital heart disease in Chile. PLoS ONE. 2020;15(10):e0240383.

61. Soufi A, Gouton M, Metton O, Mitchell J, Bernard YF, Bozio A, et al. Quality of life of adult Fontan patients. Cardiol Young. 2021;31(1):97-104.

62. Connor B, Osborne W, Peir G, Smith M, John A. Factors associated with increased exercise in adults with congenital heart disease. Am J Cardiol. 2019;124(6):947-51.

63. Riehle-Colarusso T, Autry A, Razzaghi H, Boyle CA, Mahle WT, Van Naarden BK, et al. Congenital heart defects and receipt of special education services. Pediatrics. 2015;136(3):496-504

64. Gaetano D, Gargiulo PPB, Careddu L, Egidy-Assenza G, Angeli E, Calcaterra G. What have we learnt 50 years after the first Fontan procedure? J Cardiovasc Med Hagerstown. 2020;21(5):349-58

65. Stegeman R, Lamur KD, van den Hoogen A, Breur J, Groenendaal F, Jansen NJG, et al. Neuroprotective drugs in infants with severe congenital heart disease: a systematic review. Front Neurol. 2018;9:521.

66. Grech V, Gatt M. Syndromes and malformations associated with congenital heart disease in a population-based study. Int J Cardiol. 1999:68(2):151-6.

67. Shillingford AJ, Glanzman MM, Ittenbach RF, Clancy RR, Gaynor JW, Wernovsky G. Inattention, hyperactivity, and school performance in a population of school-age children with complex congenital heart disease. Pediatrics. 2008;121(4):e759-67.
68. Barbaresi WJ, Katusic SK, Colligan RC, Weaver AL, Jacobsen SJ. Longterm school outcomes for children with attention-deficit/hyperactivity disorder: a population-based perspective. J Dev Behav Pediatr. 2007;28(4):265-73.

69. Joshi M, Tulloh RM. Respiratory virus prophylaxis in congenital heart disease. Future Cardiol. 2018;14(5):417-25.

70. Cahill TJ, Jewell PD, Denne L, Franklin RC, Frigiola A, Orchard E, et al. Contemporary epidemiology of infective endocarditis in patients with congenital heart disease: a UK prospective study. Am Heart J. 2019:215:70-7.

71. Giuseppe CAC, Guccione P, Di Salvo G, Bassareo PP. Infective endocarditis triangle. Is it the time to revisit infective endocarditis susceptibility and indications for its antibiotic prophylaxis. Eur J Prev Cardiol. 2019;26(16):1771-4.

72. Lawlor DA, Tilling K, Davey SG. Triangulation in aetiological epidemiology. Int J Epidemiol. 2016;45(6):1866-86.

73. IntHout J, loannidis JP, Rovers MM, Goeman JJ. Plea for routinely presenting prediction intervals in meta-analysis. BMJ Open. 2016;6(7):e010247.

74. project L. https://lifecycle-project.eu/.

\section{Publisher's Note}

Springer Nature remains neutral with regard to jurisdictional claims in published maps and institutional affiliations.
Ready to submit your research? Choose BMC and benefit from:

- fast, convenient online submission

- thorough peer review by experienced researchers in your field

- rapid publication on acceptance

- support for research data, including large and complex data types

- gold Open Access which fosters wider collaboration and increased citations

- maximum visibility for your research: over $100 \mathrm{M}$ website views per year

At BMC, research is always in progress.

Learn more biomedcentral.com/submissions 